\title{
HOMENAGENS
}

\section{RICHARD RORTY, ARAUTO DE UMA NOVA VISÃO DE MUNDO}

\author{
Paulo Roberto Margutti Pinto* \\ paulomargutti@terra.com.br
}

O ano de 2007 trouxe grandes perdas para a filosofia. Dentre elas, destacase aquela marcada pelo falecimento de Richard Rorty, no dia 08 de junho, em sua residência em Palo Alto, na Califórnia, aos 75 anos, de câncer no pâncreas.

Rorty nasceu em New York, em 1931. Seus escritos revelam a influência das idéias social-democráticas de seus pais, que eram escritores e militantes políticos inspirados no pensamento socialista. No texto Trotsky e as Orquídeas Selvagens, Rorty nos fala não apenas dessa influência, mas também de seu interesse, desde a infância, pelas orquídeas selvagens, que ele considerava flores sem utilidade social. A partir daquela época, seu objetivo em filosofia tem sido encontrar um equilíbrio entre duas tendências opostas: a defesa da pureza intelectual no estilo de seus pais e a contemplação da beleza pura.

Nosso filósofo foi um estudante precoce, tendo ingressado na Universidade de Chicago aos 15 anos de idade. Isso lhe permitiu não só escapar das truculências de que era vítima por parte dos valentões da escola secundária, mas também dedicar-se à leitura dos grandes clássicos do pensamento. Em 1952, Rorty terminou o mestrado em filosofia em Chicago e ingressou na Universidade de Yale para fazer o doutorado, que terminou em 1956. Depois

* Professor Titular da Faculdade J esuíta de Filosofia e Teologia, Belo Horizonte, Brasil.

KRITERION, Belo Horizonte, nº 116, Dez/2007, p. 527-531. 
de completar o serviço militar, deu aulas em Wellesley e depois em Princeton, de 1961 a 1982. Em seguida, lecionou na Universidade de Virgínia, até 1998. Tornou-se então professor de literatura comparada em Stanford até 2005, quando se aposentou definitivamente. Rorty casou-se com Amelie-Oksenberg Rorty, de quem se divorciou. Casou-se depois com Mary Varney Rorty. Deixou três filhos - um do primeiro casamento e dois do segundo - e dois netos.

Como filósofo, Rorty foi um pensador impressionantemente produtivo e combativo. Sua filosofia tem inúmeras fontes, como James, Dewey, Quine, Sellars, Davidson, Darwin, Hegel, Heidegger e Wittgenstein. Rorty se autodefine como um neopragmatista, porque não apenas se baseia nas idéias de Dewey e James, mas também as renova, ao alegar que o termo experiência deve ser substituído por linguagem, que é uma palavra mais adequada para expressar o holismo e o antifundacionismo desses autores. Com isso, ele abre o seu pragmatismo às contribuições enriquecedoras de filósofos analíticos como Quine, Sellars e Davidson.

Para ilustrar o legado filosófico extremamente rico e nuançado de Rorty, consideremos, por exemplo, sua concepção de linguagem, que constitui um desenvolvimento de algumas das idéias de Davidson. Em sua abordagem, Rorty considera que o eu e o mundo não podem ser descritos em termos essenciais. Eles são antes produzidos por uma série de crenças e desejos, que Rorty denomina vocabulários. A verdade não está "fora" da linguagem, pois uma crença (que pertence à linguagem) só pode ser justificada por meio de outra crença (que também pertence à linguagem). $\mathrm{O}$ domínio exterior à linguagem é formado por causas, não por razões. E o fato de estarmos em relações causais com o mundo não envolve representações em sentido tradicional. Assim, a mudança de um vocabulário para outro não tem necessariamente uma explicação racional e as novas metáforas que substituem as antigas são causas, não razões para mudanças de crenças. Ainda seguindo Davidson, Rorty considera que a metáfora é um ruído não costumeiro. Ela é uma enunciação que quebra regras, não se conformando ao jogo de linguagem e conduzindo a comunidade para um novo jogo.

A partir daí, podemos concluir que não há uma visão privilegiada do mundo, que nos forneça condições para estabelecer relações seguras entre as coisas e nossas crenças a respeito delas. Não pode haver controle dessas crenças com base nos estímulos físicos extra-lingüísticos (o mundo e o ego estão definitivamente perdidos). $\mathrm{O}$ ego é uma teia de crenças e desejos sem centro que estão continuamente mudando através dum processo de re-tecer, o qual se dá através da percepção, da inferência e da metáfora. O choque produzido pelas metáforas nos leva a re-tecer os padrões de nossas crenças 
para que possamos usá-las ao lidar com as coisas ao nosso redor. Um ruído não familiar - a metáfora, por exemplo - pode funcionar como causa para uma crença. Só depois que a metáfora perde sua estranheza e começa a ser contextualizada no interior da rede de crenças e desejos é que ela vem a constituir uma justificativa racional.

Como se pode ver, o neopragmatismo rortyano é uma forma de naturalismo. Rorty argumenta que a filosofia moderna acerta ao abandonar a visão de mundo religiosa, mas erra ao substituir a noção de Deus pela de verdade objetiva. Isso leva os modernos a manter equivocadamente a noção de fundamento último. Ora, a crítica de Sellars ao "mito do dado" mostra que a teoria da verdade como correspondência e o representacionismo são equivocados, devendo ser substituídos por uma explicação baseada na prática social. Apesar de pretenderem defender a abordagem científica, os filósofos modernos acabam por se afastar do naturalismo, que é mais compatível com seus ideais. O neopragmatismo rortyano busca superar essa deficiência, mostrando que o domínio da justificação está na prática social, que as normas provêm da sociedade e não da natureza. Somos seres biológicos num mundo natural e nossa linguagem é um instrumento para lidar com esse mundo para atingir nossos propósitos. Nessa perspectiva, a ciência é uma ferramenta eficiente, mas o cientificismo é equivocado. Já que o fundamento não está em algum princípio universal e atemporal, mas sim em formas de justificação imersas na prática social efetiva, outras formas de saber menos "científicas", como as das ciências humanas, podem ser admitidas. A melhor maneira de justificar uma crença é avaliar seu desempenho em relação a crenças alternativas. Daí a estratégia argumentativa de Rorty, que consiste em mostrar que as abordagens de seus adversários não têm um desempenho tão bom quanto a sua. Nessa forma de argumentação, a metáfora desempenha um papel vital. E a filosofia sistemática, que tenta explicar a racionalidade e a objetividade em termos de condições da representação acurada, se revela enganadora. Melhor candidata é a filosofia edificante, que ajuda as pessoas e a sociedade a se livrarem de atitudes e vocabulários desgastados pelo tempo, ao invés de fornecer um fundamento último para as instituições existentes. Embora argumente que nenhum período histórico apreendeu a realidade mais corretamente do que outro, Rorty defende a sociedade liberal-democrática como a melhor opção no momento, porque ela permite a coexistência de crenças alternativas no domínio público. Na discussão desses temas, Rorty confronta suas idéias com as de pensadores do naipe de Kant, Locke, Hegel, Quine, Sellars, Davidson, Heidegger, Habermas, Foucault e Derrida. 
Dono de um belo estilo, Rorty escreve com clareza, elegância e simplicidade, transmitindo ao leitor uma sensação de clareza racional, associada a uma esperança otimista para com o destino da humanidade. Dentre os livros mais importantes que escreveu, destacam-se A Filosofia e o Espelho da Natureza (1979), Conseqüências do Pragmatismo (1982), Contingência, Ironia e Solidariedade (1988), Objetividade, Relativismo e Verdade - Artigos Filosóficos I (1991), Ensaios sobre Heidegger e Outros - Artigos Filosóficos II (1991), Verdade e Progresso - Artigos Filosóficos III (1998), Filosofia e Esperança Social (2000). Nos três primeiros livros, Rorty expôs as linhas gerais de sua filosofia. Depois disso, escreveu uma pletora de artigos, que desenvolvem essa filosofia nos mais variados domínios e foram reunidos nos quatro livros seguintes. $\mathrm{O}$ aspecto mais importante de seu maior legado está no tipo de pragmatismo que propôs, sempre voltado para o futuro e preocupado com formas cada vez melhores de justificação. Nessa perspectiva, a filosofia constitui uma conversação sem fim, sujeita a variações contingentes. E, nessa conversação, digna de nota é a disponibilidade de Rorty para ouvir as vozes dos interlocutores "menores".

As posições heterodoxas e perturbadoras de Rorty, apontando na direção de um mundo sem referenciais fixos, despertaram as críticas de muitos autores. Dennett, por exemplo, pensa que a recusa de Rorty em reconhecer o poder da ciência para retratar a realidade revela uma ignorância intransigente dos métodos comprovados na investigação científica da verdade. Blackburn atribui a Rorty um dom extraordinário de esconder, embaralhar e lançar fumaça. Bernard Williams acusa Rorty de ser um relativista para quem a verdade se tornou dispensável. Dentre outros autores que criticam as posições de Rorty, destacam-se Putnam, McDowell, Conant, MacIntyre, Nagel, Searle e Habermas. No Brasil, as idéias de Rorty foram bastante discutidas. E aqui também as críticas aparecem em maior número do que os elogios. A razão disso está em que a maior parte dos interlocutores de Rorty, sejam eles estrangeiros ou brasileiros, fazem uma leitura relativista de sua filosofia, como se pode ver pelos exemplos acima. Mas talvez ele não tenha sido adequadamente compreendido. Para Rorty, o abandono da noção de verdade objetiva não constitui necessariamente um mal. Com efeito, a justificação contingente permite não apenas a satisfação de objetivos práticos, mas também deixa em aberto a possibilidade de futuras reformulações, motivadas por novos desafios surgidos a partir das interações com as coisas mundanas. Ora, isso constitui uma mensagem de esperança, não de desespero. De qualquer modo, o intenso debate em torno das idéias de Rorty revela a importância das mesmas para a filosofia contemporânea. 
Apesar de ocupar uma posição de destaque no quadro filosófico contemporâneo, Rorty nunca se deixou fascinar pela própria fama. Sempre foi uma pessoa modesta, simples e discreta. Quando tivemos a oportunidade de conhecê-lo pessoalmente, por ocasião de um congresso, em 1997, na UFMG, sua postura respeitosa, generosa e atenciosa contrastava com a das demais estrelas internacionais presentes. Que todos os seus leitores, sejam eles favoráveis ou não às suas idéias, possam ao menos aprender essa lição de humildade, esperança e solidariedade. 